\title{
Fish and sea urchin grazing opens settlement space equally but urchins reduce survival of coral recruits
}

\author{
Jennifer K. O'Leary ${ }^{1,3, *}$, Donald Potts ${ }^{1}$, Kathryn M. Schoenrock ${ }^{1}$, \\ Timothy R. McClahanan ${ }^{2}$ \\ ${ }^{1}$ Department of Ecology and Evolutionary Biology, University of California, Santa Cruz, California 95064, USA \\ ${ }^{2}$ Marine Programs, Wildlife Conservation Society, Bronx, New York 10460, USA \\ ${ }^{3}$ Present address: Hopkins Marine Station, Stanford University, Pacific Grove, California 93950, USA
}

\begin{abstract}
Grazing fishes and invertebrates are influential in marine ecosystems because they open space for benthic recruits, alter post-settlement recruit survival, and can often determine benthic community composition. On tropical reefs, grazing fishes and sea urchins can play key roles in limiting growth of fleshy macro-algae, thereby facilitating coral recruitment and maintaining coral-dominated communities. However, as grazer abundance increases, grazer influence on corals (or other settlers) may shift from being positive and indirect by reducing space competitors, to being negative and direct by damage or removal of coral recruits. Fishing can alter both the abundances and types of dominant grazers, with potential cascading effects on coral recruitment and subsequent community organization. In Kenya, sea urchins dominate grazing on heavily fished reefs, while herbivorous and omnivorous fishes dominate grazing within fisheries closures (marine protected areas). We used reefs under these 2 fishery management systems to investigate the effects of fish versus sea urchin grazing on the availability of settlement substrate for corals, subsequent coral settlement, and mortality of coral recruits. Fish and sea urchin grazers were equally effective at clearing benthic space for coral settlement. However, grazing associated with high densities of sea urchins on fished reefs removed many coral recruits after settlement. In contrast, fish grazing within fisheries closures enhanced coral survival compared to non-grazed treatments. We conclude that the effects of reduced abundance of grazing fishes (on available space for coral settlement) may be initially offset by increased sea urchin grazing, but that higher urchin abundances may ultimately reduce coral cover by their negative influence on post-settlement survival.
\end{abstract}

KEY WORDS: Coralline algae $\cdot$ Diadema $\cdot$ Herbivory $\cdot$ Predation $\cdot$ Phase shifts $\cdot$ Trophic cascades Marine protected areas $\cdot$ Western Indian Ocean $\cdot$ Kenya

\section{INTRODUCTION}

In marine environments, grazing by herbivores, omnivores, and micro-predators can strongly influence both settlement and post-settlement success of benthic organisms (Dayton 1971, Connell 1985, Hunt \& Scheibling 1997, O'Connor et al. 2011). The avail- ability of open space for settlement is often an indirect effect of grazing, which removes competitors and reduces the accumulation of sediments. For example, in temperate intertidal or subtidal systems, adult abalone in California as well as some Atlantic South African sea urchins promote abalone settlement by creating settlement space and removing 
sediment (Day \& Branch 2002, Miner et al. 2006). Grazers can also have direct effects on settled organisms through feeding on or dislodging new recruits. Intertidal herbivorous limpets, for example, have been shown to incidentally dislodge new barnacle recruits (Connell 1961, Stimson 1970). Grazers may also increase post-settlement survival indirectly by removing competing benthic organisms that can overgrow new settlers. Consequently, changes in the type or abundance of the dominant grazer can cause large community shifts through multiple pathways (Babcock et al. 1999, Mumby 2006, Hughes et al. 2007, Salomon et al. 2007, Duffy et al. 2003).

On tropical coral reefs, grazing fishes and sea urchins often have key roles in limiting fleshy macroalgal growth, thereby indirectly facilitating coral recruitment and maintaining coral dominance (Edmunds \& Carpenter 2001, Wright et al. 2005, Mumby et al. 2007, Coma et al. 2011). When grazers are scarce, space for coral recruitment is reduced and recruits tend to be outcompeted and overgrown by fastergrowing organisms. However, new coral recruits are highly vulnerable to removal by grazing when omnivorous fishes (especially parrotfish) or sea urchins are highly abundant (Rotjan \& Lewis 2008, McCauley et al. 2010, Cover 2011, Penin et al. 2011). Intense sea urchin grazing can also act to reduce coral recruitment indirectly by reducing the quantity and altering the species composition of crustose coralline algae (O'Leary \& McClanahan 2010, O'Leary et al. 2012), a strongly preferred settlement substrate for many corals (Morse et al. 1994, Heyward \& Negri 1999, Harrington et al. 2004).

Various biological or anthropogenic factors, such as disease or fishing, can alter both the type and the abundance of the dominant grazers. For example, following the massive die-off of Diadema antillarum in the 1980s, fish grazing has dominated most Caribbean reefs (Lessios 1988, Hughes 1994). Fishing and management can alter grazer dominance where both fish and sea urchin grazers remain abundant, as in many Indo-Pacific reefs (McClanahan et al. 1994, Harborne et al. 2009, Vermeij et al. 2010, Dee et al. 2012). On Kenyan reefs in the Western Indian Ocean, for example, grazing fishes are abundant only in fisheries closures (i.e. fully protected national marine protected areas, MPAs), while sea urchins are much more abundant on fished reefs where predatory fishes have been removed (McClanahan et al. 2007). Altering the abundance and types of grazers can have subsequent effects on recruitment processes, including those of important foundational taxa, such as corals. Reefs where both fish and sea urchin graz- ers are abundant offer opportunities to investigate the relative effects and the pathways of influence of these grazers (McClanahan \& Muthiga 1989). Such information is likely to become increasingly important for management of reefs, especially in the Caribbean, as $D$. antillarum recovers and potentially becomes the dominant grazer (Idjadi et al. 2010). While several studies have looked at the combined and differential effects of grazers on (1) removal of algae (McClanahan 1997), (2) benthic composition of reefs (Smith et al. 2010, Sjöö et al. 2011), and (3) erosion of reefs (Peyrot-Clausade et al. 2000, Carreiro-Silva \& McClanahan 2001), few empirical investigations have distinguished between the effects of fish and sea urchin grazing on early coral recruitment (Mapstone et al. 2007).

Understanding the mechanisms through which grazing either promotes or inhibits coral recruitment requires an experimental design that isolates the grazers' influences at pre- and post-settlement stages. We took advantage of reefs in Kenya where fisheries management has created areas strongly dominated by either fish or sea urchin grazers. We used an orthogonal (fully crossed) experimental design to quantify how fish and sea urchin grazers influence coral recruitment indirectly (by changing availability of settlement habitat and competitive dynamics), and directly (through subsequent removal of recruits). Based on previous findings, we hypothesized that fish grazing would allow higher coral recruitment than sea urchin grazing, and we made 4 specific stage-dependent and mechanistic predictions:

(1) Fish and sea urchin grazing both increase space available for coral recruitment.

(2) Space cleared by fish versus sea urchin grazing differs in quality: sea urchins create more bare or algal turf substrate, while fish create more crustose coralline algal (CCA) substrate.

(3) Increased CCA cover increases coral recruitment.

(4) Post-settlement mortality of recruits is higher under sea urchin than fish grazing, due to greater direct removal of newly settled corals by urchins.

\section{MATERIALS AND METHODS}

\section{Study sites}

The experimental sites were in the Kenyan back reef lagoon protected by a fringing reef spanning $250 \mathrm{~km}$ of the coast from Malindi in the north to the Tanzanian border in the south (Fig. 1) (McClanahan 


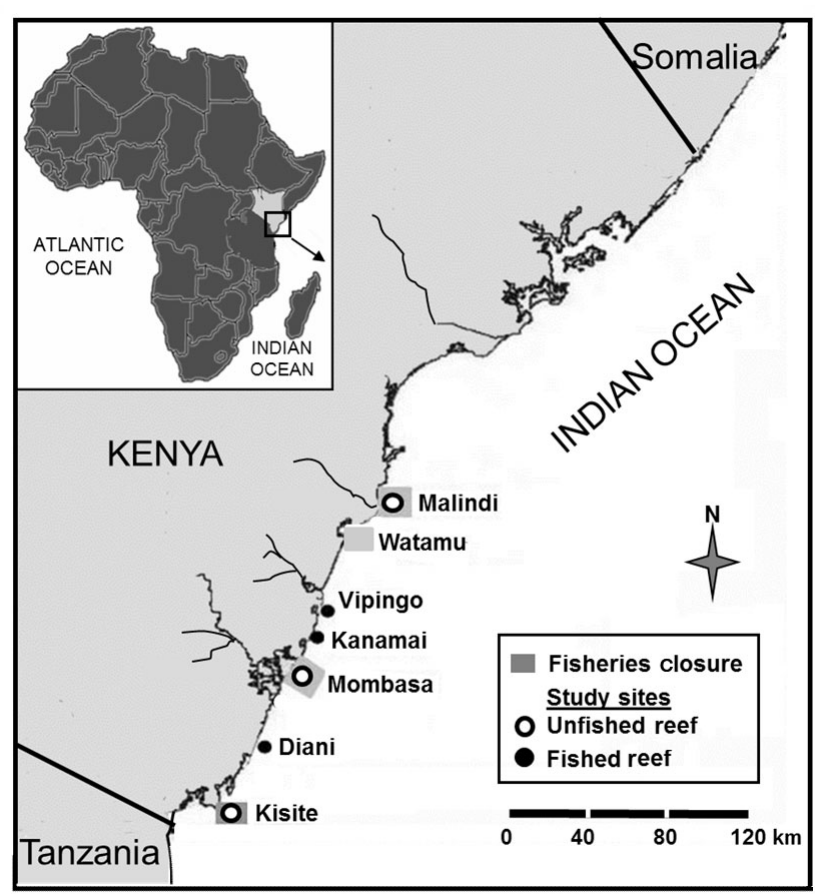

Fig. 1. Kenyan coastline showing fisheries closures and study sites

\& Arthur 2001). Most of the lagoon is $<2 \mathrm{~m}$ deep at low tide, with a $4 \mathrm{~m}$ tidal range during spring tides. The Kenyan reef system has 4 well-enforced fisheries closures (Malindi, Watamu, Mombasa, and Kisite MPAs) in which all fishing had been prohibited for more than 15 yr before this study (Fig. 1). On these unfished reefs, fish biomass is 2 orders of magnitude greater than on open access, fished reefs (McClanahan 2008). We used 3 fisheries closures (Malindi, Mombasa, and Kisite) and 3 nearby fished reefs (Vipingo, Kanamai and Diani) for experiments (Fig. 1). We excluded the Watamu fisheries closure from our experiment because this MPA is small, experiences high sediment input from a nearby estuary, and has had very low coral recruitment in recent years (J. K. O'Leary pers. obs.).

There are 2 distinct and predictable seasons on Kenyan reefs: the northeast and southeast monsoons, caused by movement of the Inter-Tropical Convergence Zone, but no hurricanes or tropical cyclones (McClanahan 1997, 1988). The NE monsoon season (October through April) is characterized by warmer waters, a shallower thermocline, less water column mixing and wave energy, slower currents, higher salinity, and higher nitrogen then the SE monsoon season (McClanahan 1988). Standing crops of macroalgae are lower during the NE than the SE monsoon season (McClanahan 1997).
In fisheries closures, surgeonfish (Acanthuridae) and parrotfish (Scarinae) are the main consumers of algae, while the triggerfish Balistapus undulatus is the predominant predator of sea urchins (McClanahan \& Shafir 1990, McClanahan 2000). Adjacent fished reefs have few predatory or herbivorous fishes; the primary algal grazers are 9 species of sea urchins, with a combined biomass 2 orders of magnitude higher than in fisheries closures (McClanahan 1997, 2008). The unfished reefs are topographically more complex, and both reef-building corals and CCA are more abundant than on fished reefs (McClanahan 2008, O'Leary \& McClanahan 2010). Since a major bleaching event in 1998, dominant corals in fisheries closures have been massive Porites and various Faviidae, plus branching Pocillopora and the Porites subgenus Synaraea. The dominant corals on fished reefs are branching and massive Porites, Stylophora, and Pavona (McClanahan 2008).

Though very few detailed studies on the timing of coral spawning have been carried out in the Western Indian Ocean, studies have been done for some corals on Kenyan reefs, including Acropora (spawns October through April; Mangubhai \& Harrison 2009), Platygyra (major period in February-March; Mangubhai \& Harrison 2008), Echinopora gemmacea (February-April; Mangubhai 2009) and Leptoria phrygia (December-February; Mangubhai 2009). Though these do not represent the dominant corals in the ecosystem, based on this data we determined that the primary spawning season likely occurs in Kenya during the NE monsoon season from October through April.

\section{Assessment of fish and sea urchin populations}

We used data from an annual monitoring program led by T. McClanahan of the Wildlife Conservation Society to evaluate fish and sea urchin abundance. Visual fish censuses were conducted during neap tides using 4 replicate $5 \times 100 \mathrm{~m}$ belt transects per site (McClanahan \& Kaunda-Arara 1996) between August and October of 2007. Each fish was identified to species and its length was estimated to the nearest $10 \mathrm{~cm}$. Small or cryptic taxa such as blennies and gobies were not included in analyses. Biomass (wet mass; $\mathrm{kg} \mathrm{ha}^{-1}$ ) was estimated by family from length-weight correlations previously measured at local fish landing sites in Kenya (McClanahan \& Kaunda-Arara 1996). We tested for differences in total fish biomass and the biomass of the major groups of grazing fish (Acanthuridae and Scarinae) 


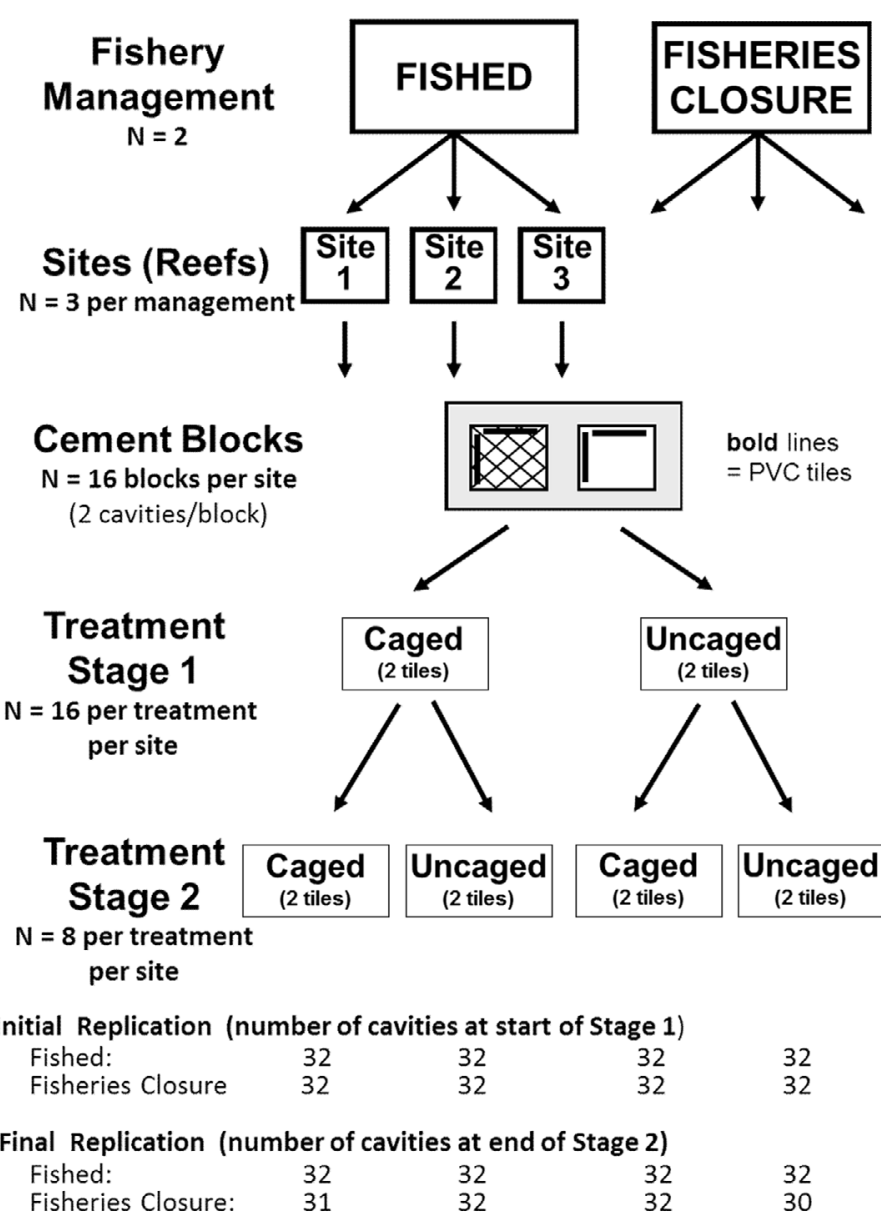

Fig. 2. Experimental design showing replication numbers

using two 1-way ANOVAs with biomass as the dependent and fisheries management (fished or closed) as the independent variable. The size distribution of Acanthuridae and Scarinae were evaluated to determine the proportion of the population that could conceivably graze within experimental coral recruitment cavities.

We used data from an annual monitoring program to estimate sea urchin density and biomass in 9 nonoverlapping, circular $10 \mathrm{~m}^{2}$ areas at 2 locations per reef site (McClanahan \& Shafir 1990) between February and March of 2007, and 2008 at each site except Kisite, which was surveyed in February 2006 and March 2008. The center of each area was determined haphazardly by tossing a weight. Sea urchins were counted and identified to species, and densities were averaged for each location at a site. Biomass $\left(\mathrm{g} \mathrm{m}^{-2}\right)$ of each species was estimated by multiplying the average density by the average wet mass of 20 to
200 haphazardly selected individuals per species (depending on abundance). Biomass samples were collected only at fished reefs, as we have not observed large differences in urchin size among reefs (T. McClanahan unpubl. data). We tested for differences in sea urchin biomass using a 1-way ANOVA with biomass as the dependent and fisheries management as the independent variable.

\section{Experimental design}

We used a 2-stage sequential design to decouple the effects of fish and sea urchin grazing on development of potential settlement substrates (Stage 1) from the effects of post-settlement mortality (Stage 2; Fig. 2). During the first 6 mo (Stage 1; April to October 2007) benthic communities became established on experimental surfaces (PVC tiles) in 2 grazing treatments (ungrazed and grazed) created by caging in both fisheries management treatments (fished and unfished reefs). Fished reefs represent reefs where sea urchins were the dominant grazers, and unfished reefs represent reefs where fishes were the dominant grazers. At the end of Stage 1, just before the main coral recruitment season began, we recorded the community present on tiles under each regime. Prior to Stage 2, half of the treatments at each site were swapped: half of the cages around ungrazed (caged) treatments were opened to allow grazing and half of the grazed treatments were caged to prohibit grazing. The other half of treatments were left in their original state. During the 6 mo of Stage 2 (October 2007 to April 2008), corals settled on the experimental substrates and coral recruitment and substrate

Table 1. Total biomass ( $\mathrm{kg} \mathrm{ha}^{-1} \pm \mathrm{SE}$ ) of all fish (2007), herbivorous fish (2007), and all sea urchin species (2006 to 2008) at 6 study sites. Herbivorous fish are the 2 dominant herbivorous families (Acanthuridae and Scarinae)

\begin{tabular}{|c|c|c|c|c|}
\hline \multicolumn{2}{|c|}{$\begin{array}{l}\text { Management } \\
\text { Site }\end{array}$} & $\begin{array}{l}\text { Total } \\
\text { fish }\end{array}$ & $\begin{array}{l}\text { Herbivorous } \\
\text { fish }\end{array}$ & $\begin{array}{l}\text { Sea } \\
\text { urchin }\end{array}$ \\
\hline \multicolumn{5}{|c|}{ Fished reefs } \\
\hline Vipingo & 20 & $4.2 \pm 31.7$ & $9.3 \pm 1.1$ & $2817.9 \pm 307.5$ \\
\hline Kanamai & & $7.2 \pm 9.0$ & $9.5 \pm 1.6$ & $4551.5 \pm 328.5$ \\
\hline Diani & & $3.3 \pm 13.1$ & $7.0 \pm 5.6$ & $3104.9 \pm 1103.1$ \\
\hline Average & 11 & $1.6 \pm 23.1$ & $8.6 \pm 1.9$ & $3464.3 \pm 331.5$ \\
\hline \multicolumn{5}{|c|}{ Fisheries closures } \\
\hline Malindi & 1127 & $7.2 \pm 186.8$ & $221.4 \pm 27.9$ & $66.9 \pm 20.6$ \\
\hline Mombasa & 141 & $1.5 \pm 300.4$ & $185.1 \pm 26.4$ & $1059.7 \pm 168.3$ \\
\hline Kisite & 91 & $6.4 \pm 148.9$ & $164.0 \pm 45.6$ & $636.1 \pm 255.3$ \\
\hline Average & 115 & $1.7 \pm 130.9$ & $190.1 \pm 19.3$ & $587.6 \pm 153.6$ \\
\hline
\end{tabular}


community composition were evaluated for each treatment at the end of Stage 2. The sequential design made it possible to distinguish the effect of available settlement substrate (established during Stage 1 treatments) on coral recruitment from the effect of grazing on settled coral recruits (during Stage 2) under the 2 management systems dominated by different grazers (fishes and sea urchins).

The experimental surfaces were PVC tiles $(10.3 \times$ $15.7 \mathrm{~cm}$ and $2 \mathrm{~mm}$ thick) attached by a large plastic cable tie (zip tie) to the insides of cavities in concrete blocks (Fig. 2). Tiles were affixed to blocks with a cable tie inserted through the hole in the tile and the concrete block, with the head of the cable tie holding the tile in place (such that no cable tie lay across the tile), and with another cable tie attached outside the block. The area of each tile available for settlement was $159.7 \mathrm{~cm}^{2}$ (after accounting for a $5 \mathrm{~mm}$ diameter hole through which tiles were secured to blocks). Tiles were sanded before use to provide a rougher surface. Each block $(20 \times 25 \times 50 \mathrm{~cm})$ was made of concrete poured into molds to create 2 cavities $(13 \times 13 \mathrm{~cm}$ openings and $20 \mathrm{~cm}$ long) forming horizontal tunnels through the block (Fig. 2). Holes for attaching tiles and cages were made during the molding process. Each block was attached using a 50/50 mixture of cement and sand to a horizontal, dead, hard substrate within coral-dominated habitat. Blocks were $\sim 2 \mathrm{~m}$ apart and placed in a line parallel to the reef margin.

A preliminary experiment was conducted between January and April 2006 using 10 cement blocks (16 cavities) at 6 sites (Fig. 1) to determine coral settlement orientation within block cavities. In the preliminary experiment, tiles were attached to the inner top, 1 inner side, and inner bottom of each cavity as described above. Virtually all coral recruits were found on tiles in the inner top (upside-down) and inner vertical orientations, a pattern consistent with a general tendency of corals to settle on the undersides of overhangs (Wallace 1985, Raimondi \& Morse 2000, Mangubhai et al. 2007, Price 2010). Thus, in the final experiment, 2 PVC tiles were attached to the inner top and one inner side of each cavity. During both the preliminary and final experiments, both fish and sea urchins were observed grazing on the tiles within uncaged cavities. On reefs closed to fishing (MPAs), parrotfish of multiple species and the red-lined triggerfish were the dominant fish observed entering the cavities, and these had an approximate maximum length of $40 \mathrm{~cm}$. On fished reefs, open cavities typically had between 1 and 3 sea urchins within them. The most common sea urchin species observed within cavities was Diadema savignyi, with Echino- metra mathaei and D. setosum seen in cavities only occasionally.

For the experiment (2007 and 2008), we deployed 16 cement blocks (32 cavities) at each of the 6 sites in April 2007 (Fig. 1), 6 mo before the main coral settlement season. During Stage 1, each block had 2 treatments: grazed and ungrazed. Grazed cavities were open at both ends and exposed to fishes and sea urchins. Ungrazed cavities were caged at each end to exclude large grazers, using plastic garden mesh with $2.5 \times 2.5 \mathrm{~cm}^{2}$ openings. The mesh was fastened to the block with zip ties through holes made in the blocks as they were cast. The mesh was cleaned inside and out monthly throughout Stages 1 and 2 to minimize fouling that could reduce light and water movement within the caged treatments. At the end of Stage 1 (October 2007), we removed and photographed each tile, then returned it to its cavity. At the end of Stage 2 (April 2008), we removed, photographed, and air-dried all tiles and then stored them in individual plastic zip lock bags for subsequent laboratory analysis. For each Stage 1 plus Stage 2 grazing combination, the design provided 8 replicate cavities per treatment per reef.

\section{Data collection}

We used a point sampling method to estimate the area of each tile with suitable coral settlement substrate (bare or CCA) from photographs taken at the end of Stages 1 and 2. We overlaid each tile photograph with a grid of 50 uniformly distributed points (using the program CPCe; Kohler \& Gill 2006) and recorded the organism type under each point. We used the photographs of tiles taken after Stage 1 to estimate the initial area available for settlement (bare or CCA habitat) at the beginning of Stage 2. We used the photographs taken at the end of Stage 2 to estimate the final area of open space (bare and CCA) remaining at the end of the experiment on which corals could have survived without being overgrown.

Two independent observers searched each tile for coral recruits under a dissecting microscope. Each recruit was identified to family following Babcock et al. (2003). We then lifted all organisms (except coral and CCA) from the tiles, and searched for coral recruits covered by encrusting organisms. We recorded the type of organism overgrowing any covered coral recruit and the substrate beneath each coral recruit. For each coral recruit, we assumed the recruit was alive at the time of collection if it was uncovered, and that it was dead if it was overgrown. 


\section{Data analyses}

In the subsequent analyses, we averaged the number of recruits and the substrate percent cover for the 2 tiles within a single opening, so that there were 16 replicate treatments (caging $\times$ stage) per site per stage (Fig. 2). Before analyses, total recruits, live recruits, and recruit density (live recruits per open area after Stage 2) data were fourth-root transformed to meet assumptions of normality. The area of open substrate (bare and CCA) at the end of Stages 1 and 2 were each square root transformed. We used a series of linear mixed models to determine how fish and sea urchin grazing affected settlement substrate availability and post-settlement mortality. Although cement blocks (with cavities) were evenly spaced along the reef, to account for potential spatial variability along the line of cement blocks, we established 4 statistical blocks per site that we used in the linear mixed models. Each statistical block, which we termed 'group,' was made up of 4 adjacent cement blocks (8 cavities) that comprised all possible Stage 1 and 2 caging combinations.

\section{Coral settlement rates}

We evaluated whether coral settlement was different between fisheries closures and fished reefs regardless of the presence of any grazers. We did this with a linear mixed model using the total number of recruits (live and dead) at the end of Stage 2 as the dependent variable, site nested within management and group nested within site nested within management as a random factors, and management as a fixed factor (Model 1; Table 2).

\section{Effects of grazers on the amount and type of settlement substrate}

We next tested whether grazers in the 2 management systems had different effects on the quantity of suitable settlement substrate (bare and CCA) as measured at the end of Stage 1. We did this using a linear mixed model (Model 2; Table 2) with fisheries management system, Stage 1 treatment (grazed versus ungrazed), and the management $\times$ treatment interaction as fixed factors, and other organism cover, site nested within management, and group nested within site nested within management as random factors.

We then performed a linear regression analysis between the percent cover of CCA (dependent variable) and the percent cover of open space (independent variable) at the end of Stage 1. A linear relationship would indicate that the grazing treatments influenced the CCA percent cover proportionally to the cover of open substrate.

\section{Coral settlement as a function of habitat availability}

We analyzed whether the number of recruits varied as a function of the habitat created during Stage 1. Because open space and CCA cover were strongly correlated, we used open space as the dependent variable. We used a linear mixed model with the 
number of all coral recruits (live and dead) as the dependent variable, open space at the end of Stage 1 as the fixed factor, and site as the random factor (Model 3; Table 2). We also repeated this analysis using the number of live (uncovered) recruits as the dependent variable.

To determine whether coral recruits settled preferentially on CCA or bare substrate, we conducted a $\chi^{2}$ analysis. The expected distribution was determined by multiplying the total number of recruits (found at the end the experiment) by the percent cover of CCA and by the cover of bare habitats (measured at the end of Stage 1). For the observed distribution, we counted the number of recruits on each substrate type-bare and CCA.

\section{Importance of pre- and post-settlement factors in coral recruitment}

To determine if differential post-settlement mortality occurred during Stage 2, we needed to calculate recruit density for the amount of available open substrate on which recruits could still be alive at the end of the experiment. The density was thus calculated as the number of live recruits at the end of Stage 2 divided by the final area of open space on tiles at the end of Stage 2. By using this density measure, we accounted for differences in open space created in the treatments, allowing us to evaluate whether any of the experimental treatments (caging: grazer presence, and management: type of grazers) in any stage had effects on post-settlement mortality.

To determine what factors contributed to recruitment success (live recruit density), we used a linear mixed model (Model 4; Table 2) that evaluated all the factors and combinations of factors within the experiment. The dependent variable was density of live coral recruits; the fixed factors were management system, Stage 1 treatment, Stage 2 treatment, Stage 1 treatment $\times$ management, Stage 2 treatment $\times$ management, and Stage 1 treatment $\times$ Stage 2 treatment; the random factors were site nested within management, and group nested within site nested within management.

\section{RESULTS}

Photographs of 39 tiles ( $9 \%$ of tiles) at the end of Stage 1 were unusable due to camera malfunction or fogging. When the tiles were collected at the end of Stage 2, $41(11 \%)$ of the 384 tiles were missing or had broken off the block. Missing tiles and photos were distributed broadly across management regimes and treatments (Fig. 2). Because we averaged data for 2 tiles within each cement block cavity, where there was 1 tile missing within a single cavity, we simply used data for the remaining tile.

\section{Fish and sea urchin populations}

The biomass of all fish families was significantly higher on closed reefs than on fished reefs (ANOVA $\mathrm{df}=1,22, F=62.3, \mathrm{p}<0.0001$; Table 3). Similarly, the biomass of the 2 dominant grazing fish families (Acanthuridae and Scarinae) was also significantly higher on closed than on fished reefs (ANOVA $\mathrm{df}=1,22, F=87.2, \mathrm{p}<0.0001$; Table 3$)$. The size frequency distributions of the dominant fish grazer families in the system (Acanthuridae and Scarinae) showed that $95 \%$ of acanthurid grazers and $51 \%$ of scarinid grazers within fisheries closures were $<30 \mathrm{~cm}$, and could therefore graze within the experimental crevices (Fig. 3).

The biomass of sea urchins was significantly higher on fished reefs than on closed reefs (ANOVA df $=$ $1,26, F=50.0, p<0.0001$; Table 1). Similarly, the biomass of the commonly observed sea urchins within grazed treatments, Diadema savignyi, was also significantly higher on fished than on closed reefs (ANOVA df $=1,26, F=39.3, \mathrm{p}<0.0001$ ) with an average biomass of $474.8 \pm 64.3 \mathrm{~kg} \mathrm{ha}^{-1}$ on fished reefs, and $6.9 \pm 2.7 \mathrm{~kg} \mathrm{ha}^{-1}$ on closed reefs.

\section{Coral settlement rates}

The 335 tiles recovered at the end of Stage 2 contained a total of 951 coral recruits. All recruits were small, ranging between 1 and 27 polyps, with the majority $(97 \%)$ having between 1 and 3 polyps. Only 219 recruits were uncovered and alive at the end of the experiment; the remaining 732 were covered by fouling organisms. Most dead recruits (62\%) were covered by turf mixed with sediment. Other organisms covering recruits included the red alga Peyssonnelia spp. (19\% of dead recruits), sponges and tunicates $(8 \%)$, bryozoans $(7 \%)$, unidentified fleshy algae $(2 \%)$ and CCA $(0.5 \%)$. Raw data for the average numbers of recruits, density of live recruits, and amount of open space in fisheries management systems and treatment types are shown in Table 3 to allow comparisons of fish and sea urchin grazing effects with other studies. 
Table 3. Summary of data: (A) overall densities $\left(\mathrm{m}^{-2} \pm \mathrm{SE}\right.$ ) of coral recruits; (B and C) coral recruit densities and open substrate $(\%$ cover \pm SE) in each Stage $1 \times$ Stage 2 treatment on (B) fished reefs and in (C) fisheries closures

\begin{tabular}{|c|c|c|c|c|c|c|}
\hline \multicolumn{2}{|c|}{$\begin{array}{l}\text { (A) Overall recruit density } \\
\text { Management }\end{array}$} & Total recruits & Live recruits & & & $\begin{array}{l}\text { Live recruits on } \\
\text { open substrate }\end{array}$ \\
\hline \multicolumn{2}{|c|}{ Fished reefs } & $149 \pm 23$ & $31 \pm 5$ & & & $611 \pm 143$ \\
\hline \multicolumn{2}{|c|}{ Fisheries closures } & $32 \pm 6$ & $11 \pm 3$ & & & $111 \pm 28$ \\
\hline \multicolumn{7}{|c|}{ (B and C) Recruit density and open substrate } \\
\hline \multicolumn{2}{|c|}{ Treatment } & \multirow{2}{*}{$\begin{array}{l}\text { Total } \\
\text { recruits }\end{array}$} & \multirow{2}{*}{$\begin{array}{l}\text { Live } \\
\text { recruits }\end{array}$} & \multicolumn{2}{|c|}{ Open substrate (\%) } & Live recruits after \\
\hline Stage 1 & Stage 2 & & & After Stage 1 & After Stage 2 & Stage $2\left(\mathrm{~m}^{-2}\right.$ open$)$ \\
\hline \multicolumn{7}{|c|}{ (B) Fished reefs } \\
\hline Ungrazed & Ungrazed & $234 \pm 61$ & $44 \pm 17$ & $28 \pm 15$ & $15 \pm 10$ & $543 \pm 156$ \\
\hline Ungrazed & Grazed & $67 \pm 16$ & $25 \pm 12$ & $27 \pm 21$ & $26 \pm 18$ & $481 \pm 274$ \\
\hline Grazed & Ungrazed & $240 \pm 61$ & $32 \pm 5$ & $49 \pm 25$ & $19 \pm 13$ & $1054 \pm 454$ \\
\hline Grazed & Grazed & $63 \pm 17$ & $23 \pm 6$ & $43 \pm 23$ & $30 \pm 22$ & $440 \pm 214$ \\
\hline \multicolumn{7}{|c|}{ (C) Fisheries closures } \\
\hline Ungrazed & Ungrazed & $10 \pm 4$ & $3 \pm 2$ & $27 \pm 13$ & $17 \pm 11$ & $80 \pm 63$ \\
\hline Ungrazed & Grazed & $57 \pm 21$ & $21 \pm 8$ & $34 \pm 18$ & $22 \pm 11$ & $191 \pm 75$ \\
\hline Grazed & Ungrazed & $24 \pm 8$ & $7 \pm 3$ & $38 \pm 18$ & $22 \pm 17$ & $65 \pm 34$ \\
\hline Grazed & Grazed & $35 \pm 8$ & $12 \pm 4$ & $42 \pm 21$ & $31 \pm 14$ & $106 \pm 34$ \\
\hline
\end{tabular}

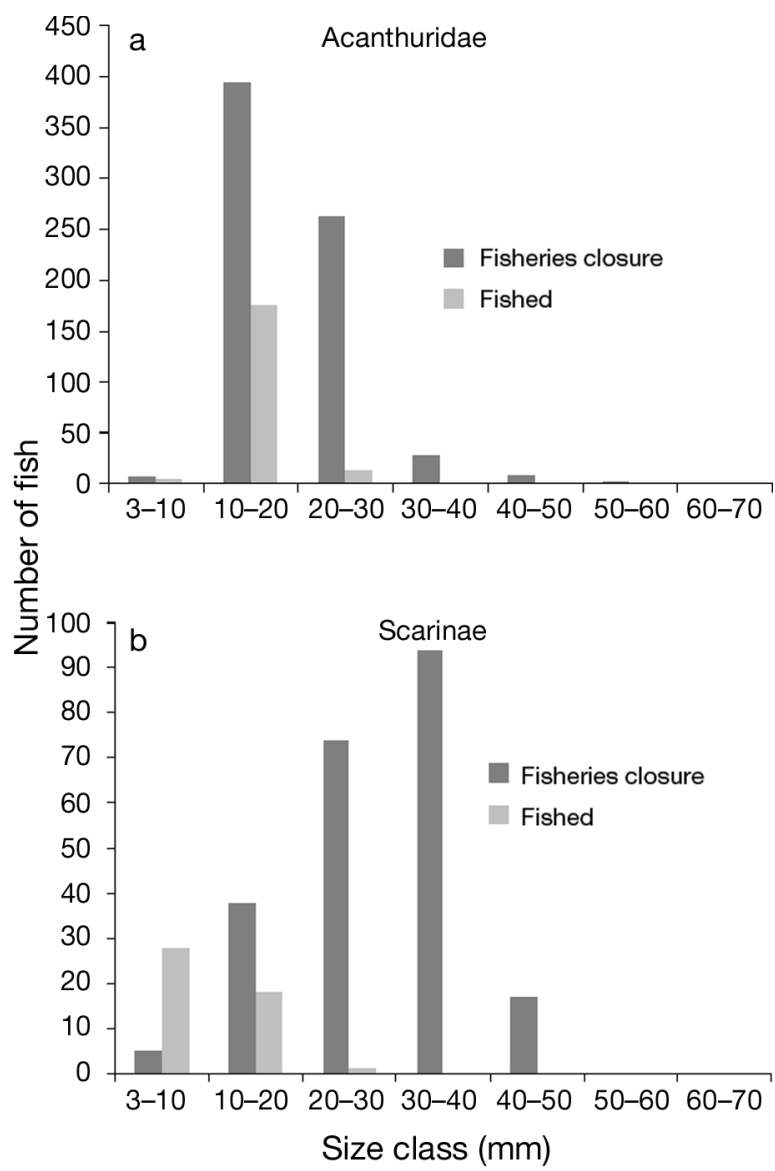

Fig. 3 Size frequency distribution of the 2 major groups of grazing fishes on Kenyan reefs (no. fish per $500 \mathrm{~m}^{2}$ ): (a) Acanthuridae (surgeonfishes) and (b) Scarinae (parrotfishes)
The vast majority of all recruits were either Pocilloporidae $(58 \%)$ or Porites $(40 \%)$. There were only 2 Acroporidae, and 11 recruits could not be identified. Of the live recruits, $74 \%$ were Pocilloporidae and $25 \%$ were Porites. Most coral recruits (89\%) were attached to CCA, and $10 \%$ of recruits were attached to bare substrate. Four recruits were on Peyssonnelia spp., 2 on barnacles, and 2 on bryozoans. The same general pattern held when we looked at only the live recruits with $91 \%$ on CCA substrate. There was no statistically significant difference in the total number of recruits (live and covered) that settled on tiles by the end of Stage 2 on fished reefs and in closed reefs (Model 1: $\mathrm{df}=1,4, F=4.22, \mathrm{p}=0.11$ ). Variance in coral settlement was 9 times greater between sites nested within management treatments than between adjacent groups of cavities (the 4 statistical blocks per site) nested within sites.

\section{Effects of grazers on the amount and type of settlement substrate}

There was no difference in the amount of open substrate created by the grazer types in the 2 management systems during Stage 1 (Model 2; Table 4). However, grazing had a strong effect on open space for both grazer types (fisheries management systems, Model 2; Table 4), with more open substrate in grazed treatments. Variance in open space was 2 times greater between sites nested within manage- 
Table 4. Results of the linear mixed model (Model 2) analyzing effects of grazing treatment (grazed and ungrazed) and grazer type (fisheries management: fished or closed) on open space for coral recruit settlement (bare and CCA substrate) at end of Stage 1

\begin{tabular}{|lrrc|}
\hline Effect & df & $F$ & $p$ \\
\hline Fisheries management & 1,4 & 2.61 & 0.63 \\
Stage 1 treatment & 1,152 & 44.67 & $<0.0001$ \\
Stage $1 \times$ fisheries management & 1,152 & 0.22 & 0.66 \\
\hline
\end{tabular}

ment treatments than between groups of adjacent cavities nested within sites. There was a strong positive correlation between the amount of open substrate and the amount of CCA substrate (linear regression analysis $r=0.93, p<0.0001$ ) indicating that over the 6 mo of Stage 1, grazers created CCA and bare substrates in similar proportions.

\section{Settlement as a function of habitat availability}

There was no correlation between the total number of coral recruits and the amount of open settlement substrate at the end of Stage 1 (Model 3a: $\mathrm{df}=1,170$, $F=0.10, \mathrm{p}=0.76$ ), or between the number of live recruits and open substrate at the end of Stage 1 (Model 3b: df $=1,170, F=2.53, p=0.11$ ). Coral recruits were found more frequently than expected by chance on CCA substrate than bare substrate $\left(\chi^{2}=\right.$ $363.1, \mathrm{df}=1, \mathrm{p}<0.001$ ), with $89 \%$ of all recruits and $91 \%$ of live recruits found on CCA substrate.

\section{Importance of pre- and post-settlement factors in recruitment}

When evaluating which experimental factors contributed to differences in the density of live coral recruits at the end of the experiment (Model 4), the interaction between the Stage 2 grazer treatment and the fisheries management system was the only significant factor ( $p=0.002$; Table 5$)$. There was a higher live recruit density in grazed treatments than in ungrazed (caged) treatments in fisheries closures with fish grazers, but there was a higher recruit density in ungrazed treatments than in grazed treatments on fished reefs with sea urchin grazers (Fig. 4). Variation in the density of live recruits was approximately 1000 times greater between sites nested within management treatments than between groups of adjacent cavities nested within sites.
Table 5. Results of the linear mixed model (Model 4) analyzing factors associated with live coral recruit densities at end of Stage 2

\begin{tabular}{|lrrl|}
\hline Effect & df & $F$ & $\mathrm{p}$ \\
\hline Fisheries management & 1,4 & 4.79 & 0.10 \\
Stage 1 treatment & 1,156 & 1.86 & 0.15 \\
Stage 2 treatment & 1,156 & 0.36 & 0.45 \\
Stage $1 \times$ Stage 2 & 1,156 & 0.07 & 0.67 \\
Stage $1 \times$ fisheries management & 1,156 & 0.66 & 0.50 \\
Stage $2 \times$ fisheries management & 1,156 & 10.06 & 0.002 \\
Stage $1 \times$ Stage 2 $\times$ management & 1,156 & 0.24 & 0.75 \\
\hline
\end{tabular}
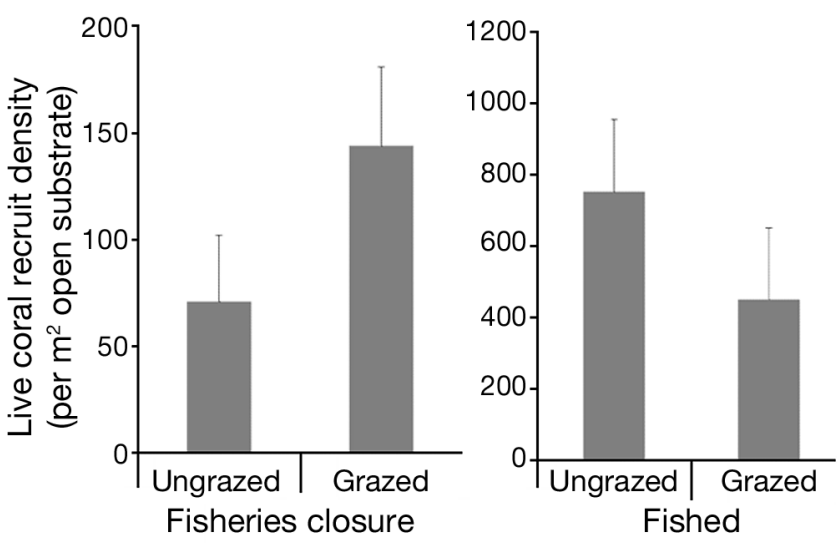

Fig. 4. Results of the linear mixed model used to determine what factors were associated with densities of live coral recruits. Here, we show the only significant factor in the model, the interaction between Stage 2 treatment and management system. Error bars are $+1 \mathrm{SE}$

\section{DISCUSSION}

Fish and sea urchin grazers can alter the amount and quality of substrate available for coral settlement, as well as the survival of newly settled recruits. As grazer abundance increases or grazer dominance changes, grazer influences may shift from positive and indirect (via promotion of settlement substrate and removal of space competitors) to direct and negative (via removal of coral recruits). We used the existing differences in the identity and abundances of dominant grazers on fished and unfished reefs to explore the differential influence of fish and sea urchin grazers on substratum and early coral settlement as well as subsequent survival. Fish and sea urchin grazers were equally effective in creating coral settlement habitat during the pre-settlement stage (Stage 1) but differentially influenced recruit densities during the post-settlement stage (Stage 2). Coral recruit density was higher in the presence of 
grazers when fish were the dominant grazers, but higher in the absence of grazers when sea urchins were the dominant grazers (Fig. 4). It appears that, at least in Kenya, sea urchin grazing is detrimental to coral recruitment due to the direct removal of recruits, but that fish grazing is beneficial overall via an indirect pathway of removing other benthic organisms (algal turf and invertebrates) that either prevent settlement or overgrow recruits.

Settlement space was not the driving factor of coral recruitment within the time frame of this study. Grazing by fishes and sea urchins equally increased space available for coral settlement by the end of Stage 1, and there was no correlation between the amount of open space and number of coral recruits settled. Furthermore, there was no indication that grazer type altered the ratio of CCA to bare substrate within cleared areas. Our previous work, investigating $18 \mathrm{yr}$ of altered grazing regimes in fished and closed reefs, contrasts with the results of this short-term study. Over longer time periods, sea urchin grazers greatly reduced the amount of CCA on fished Kenyan reefs (O'Leary \& McClanahan 2010). One possible explanation for this discrepancy is that this experiment was too short to adequately test the pre-settlement effects of grazers in establishing habitat because CCA grow slowly and therefore take much longer to become well established (McClanahan 1997). Our experiment may best represent recruit responses to newly cleared substrate rather than to climax substrate conditions that develop over long time periods. In a Caribbean coral settlement study with minimal grazing, there was a recruitment window of 9 to 14 mo after open space was created (longer than our pre-settlement Stage 1) where habitat for coral settlement was optimal (Arnold \& Steneck 2011).

Though CCA abundance did not have an influence on coral recruitment, CCA was an important settlement habitat: the majority of coral recruits $(\sim 90 \%)$ settled on CCA, regardless of grazer presence or identity. Similar results have been reported in a number of other studies (Raimondi \& Morse 2000, Harrington et al. 2004, Ritson-Williams et al. 2010, O'Leary et al. 2012). Our previous work on natural substratum in Kenya also found that corals were strongly associated with CCA in general, and specifically with 2 species of CCA in the genus Hydrolithon that are known to induce settlement of invertebrate larvae (O'Leary et al. 2012). In our previous work, coral recruitment was correlated with the cover of CCA. In this experiment, while most corals recruited to CCA, coral recruitment was not correlated with $\mathrm{CCA}$ cover. It may be that presence of inductive CCA taxa rather than absolute abundance facilitates coral recruitment. We suggest that over reef scales, inductive CCA are sparse and infrequently encountered by settling recruits, so that higher CCA cover leads to greater recruitment. Over small spatial scales, where the amount of CCA is not limiting, increasing cover of CCA may not induce further recruitment. This could be an important finding for management of grazing communities on reefs to optimize coral recruitment, and suggests the need for further controlled experiments testing whether CCA cover or the presence of inductive CCA is more important.

Fish and sea urchin grazing had significantly different influences on the post-settlement mortality of corals. The density of coral recruits was higher in the presence of grazers (fishes) within fisheries closures, but was higher in the absence of grazers (sea urchins) on fished reefs. Furthermore, the spatial distribution of grazing pressure within sites was largely uniform regardless of grazer type. There was much greater variability in grazing between sites within management systems than on smaller scales (of $\sim 16 \mathrm{~m}$ between groups of cavities within sites). For fish grazers, this finding is consistent with our previous work that showed spatial variation in fish grazing was greatest at scales of at least $1000 \mathrm{~m}$ (O'Leary \& Potts 2011). These results suggest that the mechanisms by which grazers affected coral survival were different. On Kenyan reefs, sea urchin grazing appears to be detrimental to coral recruitment by directly causing mortality of juvenile corals, while fish grazing is apparently beneficial-possibly indirectly by removing other benthic organisms (algal turf and invertebrates) that overgrow coral recruits. Sea urchins are less selective and more intense grazers than fish: they feed in a swath and ingest nonalgal materials while feeding (Lewis 1964, McClanahan 1992, Bak 1994), likely causing higher recruit removal. Coral recruit removal probably continues to be high on urchin dominated-fished reefs for at least the first 1 to 2 yr after settlement. In field studies looking at coral recruits up to $30 \mathrm{~mm}$ size, recruit density on fished reefs was half that in closed reefs, and very low overall $\left(<1 \mathrm{~m}^{-2}\right.$; O'Leary et al. 2012).

The mortality we documented for small corals (1 to 3 polyps) on fished reefs is similar to Mapstone et al.'s (2007) results in French Polynesia where sea urchins were deleterious to coral recruits at extremely high urchin densities. Our experiment demonstrates the potential influence of post-settlement processes on coral taxonomic composition. A higher proportion of Porites recruits were overgrown than pocilloporids, suggesting that pocilloporids tended to escape mor- 
tality, either by settling later or by growing faster than poritids. Arnold \& Steneck (2011) found that Porites was at a competitive disadvantage in resisting overgrowth compared to other corals, and attributed this to slow growth rates. This may mean that some juvenile corals benefit disproportionally from reduced competition under higher grazing levels. The response of coral recruitment to changes in grazing likely depends on the type and biomass of grazers, the abundance of benthic competitors, and the dominant species of coral recruits.

Literature from various regions with different grazing abundances may help identify grazer density or biomass switch points where grazer effects on coral recruitment change from indirect and positive to direct and negative. Over the last few decades, fish biomass on Kenyan reefs and possibly throughout the Western Indian Ocean has been higher than in the Caribbean (McClanahan et al. 2009). With a typical herbivore biomass of 500 to $700 \mathrm{~kg} \mathrm{ha}^{-1}$ in Kenyan fisheries closures, grazing fish have maintained a cropped substrate with $<5 \%$ cover of fleshy algae (McClanahan 1997, O'Leary \& McClanahan 2010). By comparison, after the Caribbean Diadema antillarum die-off in the 1980s, the biomass of herbivorous acanthurids and scarids ( $>12 \mathrm{~cm}$ total length) ranged from $20 \mathrm{~kg} \mathrm{ha}^{-1}$ in Jamaica to a high of $170 \mathrm{~kg} \mathrm{ha}^{-1}$ in Barbados (Williams \& Polunin 2001). Even where fish biomass was highest, fish maintained only $\sim 40$ to $60 \%$ of reef substratum in a cropped state (Williams \& Polunin 2001), and many Caribbean reefs shifted from coral dominance to fleshy algal dominance following the loss of the sea urchin D. antillarum (Lessios 1988, Hughes 1994). Furthermore, the importance of large fish grazers, particularly parrotfishes (Scarinae), has been emphasized in the literature (Lokrantz et al. 2008, Mumby et al. 2012). Our data suggest that in cryptic habitat where corals prefer to settle, smaller grazing fishes $(<30 \mathrm{~cm})$ may be equally important in maintaining open settlement space and preventing overgrowth of newly settled coral recruits. The relative importance of smaller and larger size classes of herbivorous or omnivorous fish is a potential area of future study that could guide fisheries management by elucidating the relative importance of size structure versus abundance of grazing fishes.

Some recent recovery of Diadema antillarum in the Caribbean has been reported (Carpenter \& Edmunds 2006, Mumby 2009, Idjadi et al. 2010) and thus far, it appears to be beneficial in reducing fleshy algae with the potential to increase coral recruitment and cover (Edmunds \& Carpenter 2001, Knowlton 2001, Carpenter \& Edmunds 2006, Idjadi et al. 2010). However, higher $D$. antillarum abundances may only increase coral recruitment up to some threshold of sea urchin abundance, above which coral recruitment may decline (Idjadi et al. 2010). Prior to the sea urchin die-off, effects of the $D$. antillarum on coral recruitment were apparently density-dependent. Higher coral recruit densities have been reported in plots with $\leq 12 \mathrm{D}$. antillarum $\mathrm{m}^{-2}$ (compared to control plots without D. antillarum $_{i}$ Edmunds \& Carpenter 2001, Carpenter \& Edmunds 2006), but prior to the die-off, high coral mortality was observed for Diadema densities $>16 \mathrm{~m}^{-2}$ (Sammarco 1980, 1982). This effect may be less marked for smaller urchins, such as Echinometra viridis, which had no effect on post-settlement mortality at densities up to $50 \mathrm{~m}^{-2}$ (Sammarco 1982). In our Kenyan experiment, $D$. savignyi was the most common urchin within experimental treatments on fished reefs, and it seems to have strong effects on post-settlement mortality at relatively low densities of $\sim 5 \mathrm{~m}^{-2}$.

Understanding density-dependent thresholds of urchin predation on corals may be critical for managing fisheries on coral reefs. Declines in herbivorous fish populations may be offset to some extent by increased echinoid grazing that benefits corals in the short-term by limiting overgrowth by fleshy algae or benthic invertebrates. However, at least one other study has shown that herbivorous fish are more efficient at removing fleshy algae than sea urchins, even when fish biomass was much lower than that of urchins (Jessen \& Wild 2013). Furthermore, caution is needed when making long-term projections because, in both the Caribbean (Brown-Saracino et al. 2007) and East Africa (McClanahan 1997, 1999, McClanahan et al. 2007), removal of predatory fishes that eat sea urchins has resulted in high abundances of sea urchins that are eroding the reef structure (CarreiroSilva \& McClanahan 2001, 2012), reducing CCA settlement habitat (O'Leary \& McClanahan 2010, O'Leary et al. 2012), and reducing coral recruit survival. In Kenya, both fish and sea urchin grazer densities seem to be above thresholds needed to maintain space free of fleshy algae, particularly during the cooler and less productive southeast monsoon season (McClanahan 1997). Our study suggests that maintaining higher grazing fish densities is likely to have the most beneficial effects on coral ecology by promoting coral recruitment. However, managing fisheries to increase the abundance of sea urchin predators while also restricting the capture of herbivorous fishes may reduce fisheries yields (McClanahan 1995). Evaluating the tradeoffs posed by this fisheriesecology conflict remains an important area for future investigation. 
Acknowledgements. We thank the University of California at Santa Cruz, Robert and Patricia Switzer Foundation, ARCS Foundation, Project AWARE, and the Wildlife Conservation Society for financial support. Research clearance was provided by Kenya's Ministry of Science and Technology and permission to work in the parks by the Kenya Wildlife Service. We thank J. Mariara, B. Wong, M. Goodman, C. Bednar and numerous associates who assisted with the field experiment and with laboratory sample processing. We thank P. Raimondi, M. Carr, J. Pearse, and F. Micheli for advice on experimental design and P. Raimondi for statistical advice.

\section{LITERATURE CITED}

Arnold SN, Steneck RS (2011) Settling into an increasingly hostile world: the rapidly closing "recruitment window" for corals. PLoS ONE 6:e28681

Babcock RC, Kelly S, Shears NT, Walker JW, Willis TJ (1999) Changes in community structure in temperate marine reserves. Mar Ecol Prog Ser 189:125-134

Babcock RC, Baird AH, Piromvaragorn S, Thomson DP, Willis BL (2003) Identification of scleractinian coral recruits from Indo-Pacific reefs. Zool Stud 42:211-226

Bak RPM (1994) Sea-urchin bioerosion on coral reefs: place in the carbonate budget and relevant variables. Coral Reefs 13:99-103

Brown-Saracino J, Peckol P, Curran HL, Robbart ML (2007) Spatial variation in sea urchins, fish predators, and bioerosion rates on coral reefs of Belize. Coral Reefs 26: 71-78

Carpenter RC, Edmunds PJ (2006) Local and regional scale recovery of Diadema promotes recruitment of scleractinian corals. Ecol Lett 9:271-280

Carreiro-Silva M, McClanahan TR (2001) Echinoid bioerosion and herbivory on Kenyan coral reefs: the role of protection from fishing. J Exp Mar Biol Ecol 262:133-153

> Carreiro-Silva M, McClanahan TR (2012) Macrobioerosion of dead branching Porites, 4 and 6 years after coral mass mortality. Mar Ecol Prog Ser 458:103-122

Coma R, Serrano E, Linares C, Ribes M, Diaz D, Ballasteros E (2011) Sea urchins predation facilitates coral invasion in a marine reserve. PLoS ONE 6:e22017

Connell JH (1961) The influence of interspecific competition and other factors on the distribution of the barnacle Chthamalus stellatus. Ecology 42:710-723

> Connell JH (1985) The consequences of variation in initial settlement vs. post-settlement mortality in rocky intertidal communities. J Exp Mar Biol Ecol 93:11-45

Cover WA (2011) Species interactions affecting corals and recruitment on a protected, high-latitude reef: herbivory, predation, and competition by fishes, urchins, macroalgae and cyanobacteria. PhD dissertation, University of California, Santa Cruz, CA

Day E, Branch GM (2002) Effects of sea urchins (Parechinus angulosus) on recruits and juveniles of abalone (Haliotis midae). Ecol Monogr 72:133-149

> Dayton PK (1971) Competition, disturbance, and community organization: provision and subsequent utilization of space in a rocky intertidal community. Ecol Monogr 41: 351-389

> Dee LE, Witman JD, Brandt M (2012) Refugia and top-down control of the pencil urchin Eucidaris galapagensis in the Galapagos Marine Reserve. J Exp Mar Biol Ecol 416-417:135-143

Duffy JE, Richardson JP, Canuel EA (2003) Grazer diversity effects on ecosystem functioning in seagrass beds. Ecol Lett 6:637-645

Edmunds PJ, Carpenter RC (2001) Recovery of Diadema antillarum reduces macroalgal cover and increases abundance of juvenile corals on a Caribbean reef. Proc Natl Acad Sci USA 98:5067-5071

> Harborne AR, Renaud PG, Tyler EHM, Mumby PJ (2009) Reduced density of the herbivorous urchin Diadema antillarum inside a Caribbean marine reserve linked to increased predation pressure by fishes. Coral Reefs 28: 783-791

> Harrington K, Fabricius J, De'ath G, Negri AP (2004) Recognition and selection of settlement substrata determine post-settlement survival in corals. Ecology 85:3428-3437

Heyward AJ, Negri AP (1999) Natural inducers for coral larval metamorphosis. Coral Reefs 18:273-279

> Hughes TP (1994) Catastrophes, phase-shifts, and largescale degradation of a Caribbean coral-reef. Science 265: 1547-1551

Hughes TP, Rodrigues MJ, Ceccarelli D, Hoegh-Guldberg O and others (2007) Phase shifts, herbivory, and the resilience of coral reefs to climate change. Curr Biol 17: 360-365

> Hunt HL, Scheibling RE (1997) Role of early post-settlement mortality in recruitment of benthic marine invertebrates. Mar Ecol Prog Ser 155:269-301

Idjadi JA, Haring RN, Precht WF (2010) Recovery of the sea urchin Diadema antillarum promotes scleractinian coral growth and survivorship on shallow Jamaican reefs. Mar Ecol Prog Ser 403:91-100

> Jessen C, Wild C (2013) Herbivory effects on benthic algal composition and growth on a coral reef flat in the Egyptian Red Sea. Mar Ecol Prog Ser 476:9-21

Kohler KE, Gill SM (2006) Coral Point Count with Excel extensions (CPCe): a Visual Basic program for the determination of coral and substrate coverage using random point count methodology. Comput Geosci 32:1259-1269

Knowlton N (2001) Sea urchin recovery from mass mortality: New hope for Caribbean coral reefs? Proc Natl Acad Sci USA 98:4822-4824

Lessios HA (1988) Mass mortality of Diadema antillarum in the Caribbean: What have we learned? Annu Rev Ecol Syst 19:371-393

Lewis JB (1964) Feeding and digestion in tropical sea urchin Diadema antillarum Philippi. Can J Zool 42:549-557

Lokrantz J, Nystrom M, Thyresson M, Johnansson C (2008) The non-linear relationship between body size and function in parrotfishes. Coral Reefs 27:967-974

- Mangubhai S (2009) Reproductive ecology of the scleractinian corals Echinopora gemmacea and Leptoria phrygia (Faviidae) on equatorial reefs in Kenya. Invertebr Reprod Dev 53:67-79

- Mangubhai S, Harrison PL (2008) Gametogenesis, spawning and fecundity of Platygyra daedalea (Scleractinia) on equatorial reefs in Kenya. Coral Reefs 27:117-122

Mangubhai S, Harrison PL (2009) Extended breeding seasons and asynchronous spawning among equatorial reef corals in Kenya. Mar Ecol Prog Ser 374:305-310

- Mangubhai S, Harrison PL, Obura DO (2007) Patterns of coral larval settlement on lagoon reefs in the Mombasa Marine National Park and Reserve, Kenya. Mar Ecol Prog Ser 348:149-159

Mapstone BD, Andrew NL, Chancerelle Y, Salvat B (2007) Mediating effects of sea urchins on interactions among corals, algae and herbivorous fish in the Moorea lagoon, French Polynesia. Mar Ecol Prog Ser 332:143-153 
McCauley DJ, Micheli F, Young HS, Tittensor DP and others (2010) Acute effects of removing large fish from a nearpristine coral reef. Mar Biol 157:2739-2750

McClanahan TR (1988) Seasonality in East Africa's coastal waters. Mar Ecol Prog Ser 44:191-199

McClanahan TR (1992) Resource utilization, competition and predation: a model and example from coral reef grazers. Ecol Model 61:195-215

McClanahan TR (1995) A coral reef ecosystem fisheries model: impacts of fishing intensity and catch selection on reef structure and processes. Ecol Model 80:1-19

> McClanahan TR (1997) Primary succession of coral-reef algae differing patterns on fished versus unfished reefs. J Exp Mar Biol Ecol 218:77-102

McClanahan TR (1999) Predation and the control of the sea urchin Echinometra viridis and fleshy algae in the patch reefs of Glovers Reef, Belize. Ecosystems 2:511-523

McClanahan TR (2000) Recovery of a coral reef keystone predator, Balistapus undulatus, in East African marine parks. Biol Conserv 94:191-198

McClanahan TR (2008) Response of the coral reef benthos and herbivory to fishery closure management and the 1998 ENSO disturbance. Oecologia 155:169-177

> McClanahan TR, Arthur R (2001) The effect of marine reserves and habitat on populations of east African coral reef fishes. Ecol Appl 11:559-569

McClanahan TR, Kaunda-Arara B (1996) Fishery recovery in a coral-reef marine park and its effect on the adjacent fishery. Conserv Biol 10:1187-1199

McClanahan TR, Muthiga NA (1989) Patterns of predation on sea urchin, Echinometra mathaei (Deblainville), on Kenyan coral reefs. J Exp Mar Biol Ecol 126:77-94

McClanahan TR, Shafir SH (1990) Causes and consequences of sea urchin abundance and diversity in Kenyan coral reef lagoons. Oecologia 83:362-370

> McClanahan TR, Nugues M, Mwachireya S (1994) Fish and sea urchin herbivory and competition in Kenyan coral reef lagoons: the role of reef management. J Exp Mar Biol Ecol 184:237-254

McClanahan TR, Graham NAJ, Calnan JM, MacNeil MA (2007) Toward pristine biomass: reef fish recovery in coral reef marine protected areas in Kenya. Ecol Appl 17: 1055-1067

McClanahan TR, Graham NAJ, Wilson SK, Letourneur Y, Fisher R (2009) Effects of fisheries closure size, age, and history of compliance on coral reef fish communities in the western Indian Ocean. Mar Ecol Prog Ser 396: 99-109

> Miner CM, Altstatt JM, Raimondi PT, Michinton TE (2006) Recruitment failure and shifts in community structure following mass mortality limit recovery prospects of black abalone. Mar Ecol Prog Ser 327:107-117

> Morse DE, Morse ANC, Raimondi PT, Hooker N (1994) Morphogen-based chemical flypaper for Agaricia humilis coral larvae. Biol Bull (Woods Hole) 186:172-181

Mumby PJ (2006) The impact of exploiting grazers (scaridae) on the dynamics of Caribbean coral reefs. Ecol Appl 16:747-769

Mumby PJ (2009) Phase shifts and the stability of macroalgal communities on Caribbean coral reefs. Coral Reefs 28: 761-773

> Mumby PJ, Harborne AR, Williams J, Kappel CV and others (2007) Trophic cascade facilitates coral recruitment in a marine reserve. Proc Natl Acad Sci USA 104:8362-8367

Mumby PJ, Steneck RS, Edwards AJ, Ferrari R, Coleman R, Harborne AR, Gibson JP (2012) Fishing down a Carib- bean food web relaxes trophic cascades. Mar Ecol Prog Ser 445:13-24

O'Connor NE, Donohue I, Crowe TP, Emmerson MC (2011) Importance of consumers on exposed and sheltered rocky shores. Mar Ecol Prog Ser 443:65-67

O'Leary JK, McClanahan TR (2010) Trophic cascades result in large-scale coralline algae loss through differential grazer effects. Ecology 91:3584-3597

O'Leary JK, Potts DC (2011) Using hierarchical sampling to understand scales of spatial variation in early coral recruitment. Coral Reefs 30:1013-1023

O'Leary JK, Potts DC, Braga JC, McClanahan TR (2012) Indirect consequences of fishing: reduction of coralline algae suppresses juvenile coral abundance. Coral Reefs 31:547-559

Penin L, Michonneau F, Carrol A, Adjeroud M (2011) Effects of predator and grazer exclusion on early post-settlement mortality. Hydrobiologia 663:259-264

Peyrot-Clausade M, Chabanet $\mathrm{P}$, Conand C, Fontaine MF, Letourneur Y, Harmelin-Viven M (2000) Sea urchin and fish bioerosion on La Reunion and Moorea reefs. Bull Mar Sci 66:477-485

> Price N (2010) Habitat selection, facilitation, and biotic settlement cues affect distribution and performance of coral recruits in French Polynesia. Oecologia 163:747-758

> Raimondi PT, Morse ANC (2000) The consequences of complex larval behavior in a coral. Ecology 81:3193-3211

> Ritson-Williams R, Paul VJ, Arnold SN, Steneck RS (2010) Larval settlement preferences and post-settlement survival of the threatened Caribbean corals Acropora palmata and A. cervicornis. Coral Reefs 29:71-81

Rotjan RD, Lewis SM (2008) Impact of coral predators on tropical reefs. Mar Ecol Prog Ser 367:73-91

Salomon AK, Tanape NM, Huntington HP (2007) Serial depletion of marine invertebrates leads to the decline of a strongly interacting grazer. Ecol Appl 17:1752-1770

Sammarco PW (1980) Diadema and its relationship to coral spat mortality: grazing, competition, and biological disturbance. J Exp Mar Biol Ecol 45:245-272

Sammarco PW (1982) Echinoid grazing as a structuring force in coral communities: whole reef manipulations. J Exp Mar Biol Ecol 61:31-55

Sjöö GL, Mork E, Andersson S, Melander I (2011) Differences in top-down and bottom-up regulation of macroalgal communities between a reef crest and back reef habitat in Zanzibar. Estuar Coast Shelf Sci 91:511-518

> Smith JE, Hunter CL, Smith C (2010) The effects of topdown versus bottom-up control on benthic coral reef community structure. Oecologia 163:497-507

- Stimson J (1970) Territorial behavior of owl limpet, Lottia gigantea. Ecology 51:113-118

> Vermeij MJA, Dailer ML, Walsh SM, Donaan MK, Smith CM (2010) The effects of trophic interactions and spatial competition on algal community composition on Hawaiian coral reefs. Mar Ecol 31:291-299

Wallace CC (1985) Reproduction, recruitment and fragmentation in nine sympatric species of the coral genus Acropora. Mar Biol 88:217-233

Williams ID, Polunin NVC (2001) Large-scale associations between macroalgal cover and grazer biomass on middepth reefs in the Caribbean. Coral Reefs 19:358-366

> Wright JT, Dworjanyn SA, Rogers CN, Steinberg PD, Williamson JE, Poore AGB (2005) Density-dependent sea urchin grazing: differential removal of species, changes in community composition and alternative community states. Mar Ecol Prog Ser 298:143-156 